\section{A estética política da gambiarra cotidiana} [The political aesthetics of
everyday kludges]

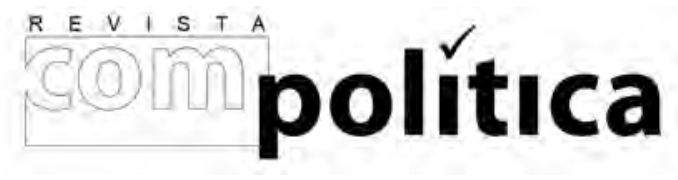

revista compolítica

2016, vol. 6(1)

compolitica.org/revista

ISSN: 2236-4781

DOI: $10.21878 /$ compolitica.2015.5.2.229

(2) Open Access Journal

\author{
Helena S. Assunção \\ Museu Nacional / UFRJ \\ [National Museum / UFRJ] \\ Ricardo Fabrino Mendonça \\ Universidade Federal de Minas Gerais \\ [Federal University of Minas Gerais]
}

\title{
Resumo
}

Neste artigo propomos pensar a gambiarra de forma ampla, como uma prática de improviso, de reapropriação de algum recurso material disponível que o transforma e adequa a uma necessidade específica. A partir disso, exploramos o processo-gambiarra para além de seu caráter funcional. Acreditamos que o rearranjo de materiais pode ressignificar nossa experiência com o mundo e reinventar o cotidiano, revelando um potencial de resistência e emancipação. As dimensões política e estética dessa prática do inusitado são tratadas, aqui, a partir da articulação das ideias de Michel de Certeau, John Dewey, Jacques Rancière e Hannah Arendt.

Palavras-chave: gambiarra; táticas; estética; política.

\section{Abstract}

This paper seeks to think of kludges and quick fixes as innovative practices, characterized by the reappropriation of available resources in order to adapt them to specific needs. It explores the process of jury rigging beyond its functional dimension. We believe that rearrangements of materials may re-signify our experiences and reinvent everyday life, disclosing potentials of resistance and emancipation. The political and aesthetic dimensions of this practice of the unusual and unexpected are dealt with through the articulation of works by Michel de Certeau, John Dewey, Jacques Rancière and Hannah Arendt.

Keywords: kludge; tactics; aesthetics; politics. 
noção de gambiarra tem como sentido original uma extensão elétrica para uso
da luz. ${ }^{1}$ No entanto, há um sentido mais amplo e genérico no qual o termo
aparece como uma prática de improviso, de reapropriação de algum recurso material disponível que o transforma e adequa a uma necessidade específica. Rodrigo Boufleur define a gambiarra como "o procedimento necessário para a configuração de um artefato improvisado" (BOUFLEUR, 2006, p.25).

Entendemos que a gambiarra está inserida nas práticas da vida cotidiana e, apesar de sua aparente trivialidade, veremos que ela apresenta um potencial estético e político, que merece atenção. Mais do que uma simples ação que modifica um produto material, a gambiarra é também uma "maneira de fazer", na acepção que Michel de Certeau dá ao termo, fugindo às regras e ao planejamento. Para além de sua funcionalidade, a gambiarra possui outras dimensões dignas de estudo. Este texto busca abordar as dimensões políticas e estéticas dessas práticas do inusitado.

$\mathrm{O}$ artigo está estruturado em três seções. $\mathrm{Na}$ primeira delas, realizamos uma breve discussão do interesse artístico e teórico sobre a noção de gambiarra. Na segunda, exploramos a conexão entre gambiarras e a ideia de Certeau de táticas cotidianas. Na terceira, abordamos a dimensão estético-política de tais táticas, recorrendo às ideias de Rancière, Dewey e Hannah Arendt. Contribuirão para essa articulação algumas remissões ilustrativas a gambiarras.

\section{Artefatos poéticos}

O interesse contemporâneo pelo tema da gambiarra pode ser notado em diversas obras, exposições e estudos. Pode-se citar, por exemplo, a exposição do paraense Emmanuel 
Nassar, intitulada "A Poesia da Gambiarra",2, e a mostra de diversos artistas realizada na FirstsideGallery na Inglaterra com o nome "Gambiarra: the New ArtfromBrazil". ${ }^{3} \mathrm{Na}$ interseção entre arte e tecnologia, "pululam" experimentos autointitulados como gambiarras, como os relatados por Ricardo Rosas ${ }^{4}$, que aponta para as múltiplas e criativas produções das novas mídias e comunidades de software livre. Também ilustrativo deste fenômeno é o coletivo Gambiologia, voltado à produção de artefatos multifuncionais. ${ }^{5}$

Gambiologia é um trabalho de construção de eletrônicos com sotaque antropofágico. Por meio de aparelhos reciclados, traz um novo significado para o contexto tecnológico, ao assumir uma postura de recontextualização criativa de materiais normalmente entendidos como refugo. A elaboração de artefatos de maneira improvisada retrata a espontaneidade do cotidiano das metrópoles e propõe uma reflexão sobre a perecibilidade, deteorabilidade e reinvenção da tecnologia, em um contexto em que o excesso de objetos fora de uso acumulados sobre a superfície do globo é uma questão crucial (por Marcus Bastos). ${ }^{6}$

Se há uma tendência a explorar as possibilidades de experimentação das gambiarras tecnológicas, é preciso lembrar que gambiarras continuam a atravessar a vida cotidiana em suas múltiplas dimensões. É o que busca evidenciar o artista plástico e cineasta Cao Guimarães em alguns trabalhos recentes. Sua série fotográfica intitulada "Estética da Gambiarra", composta entre 2001 e 2012 e exposta nos Estados Unidos, na Espanha e no Brasil, é composta por várias imagens que retratam formas, práticas e processos ordinários definidos como gambiarras. ${ }^{7}$ A série inclui fotografias variadas como a de um clipe que remenda um sutiã [imagem 1], a de um coco utilizado como travesseiro [imagem 2], a de um pregador de roupa usado para segurar a partitura nas costas de outro músico [imagem 3], o arame que conserta os óculos [imagem 4] ou a batata que vira suporte de pedidos na mesa de bar [imagem 5]. ${ }^{8}$ 


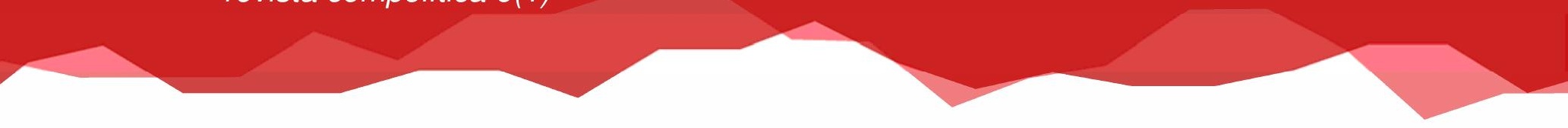

Figura 1 - O sutiã-clipado

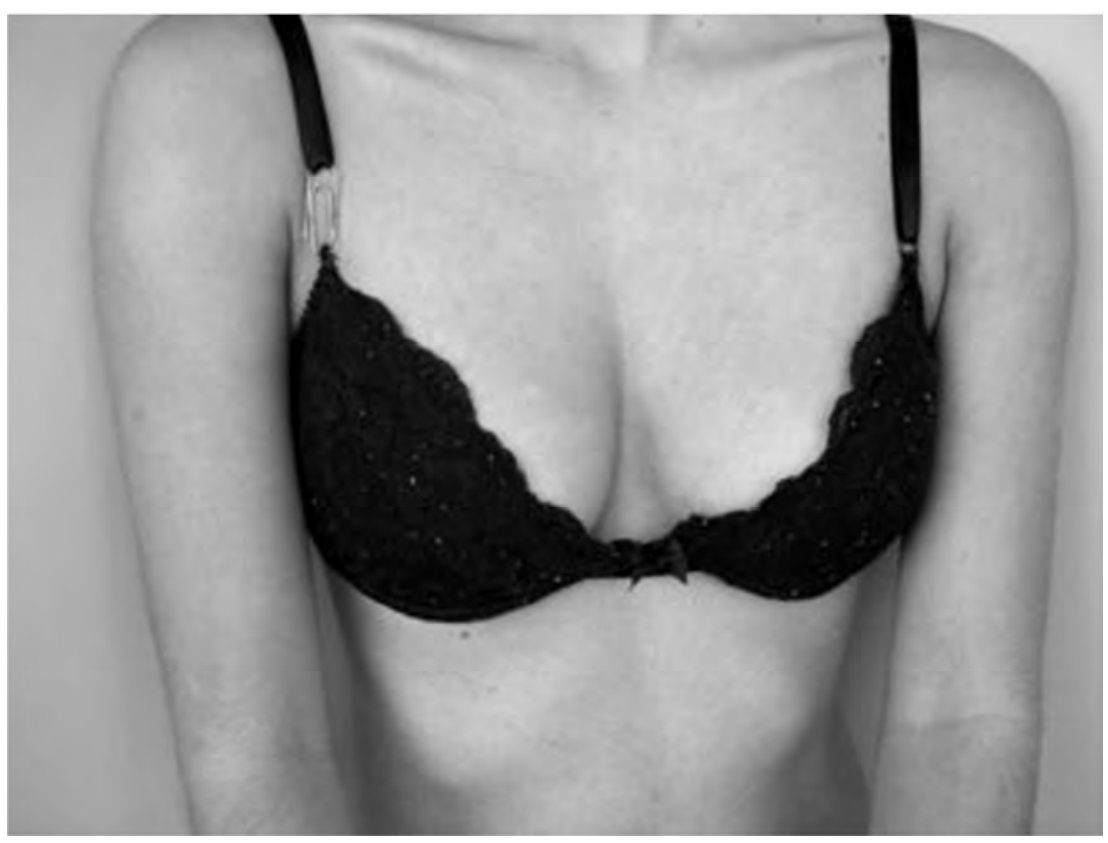

Fonte: Cao Guimarães.

Figura 2 - O travesseiro-coco

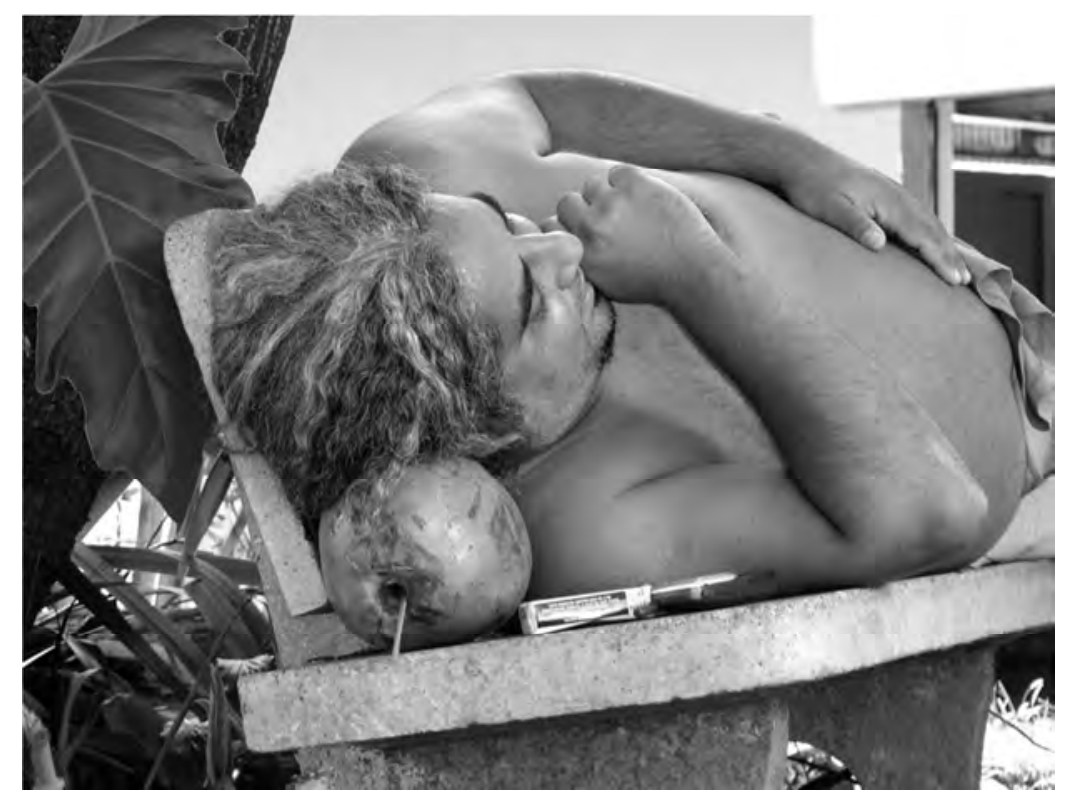

Fonte: Cao Guimarães. 
Figura 3 - As costas-partitura

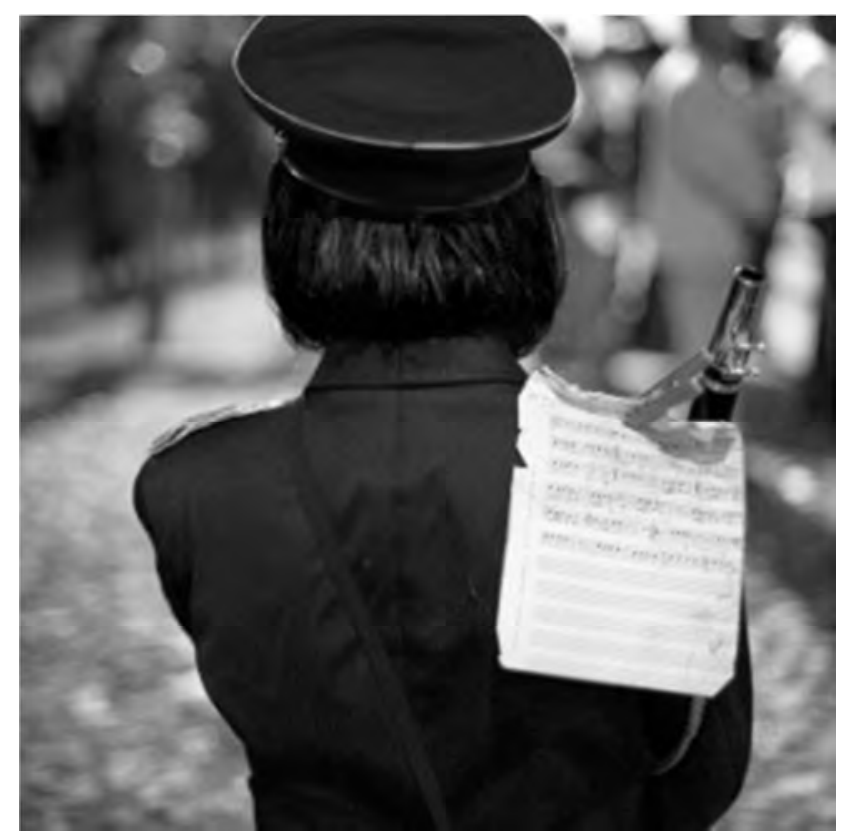

Fonte: Cao Guimarães.

Figura 4-Os óculos-arame

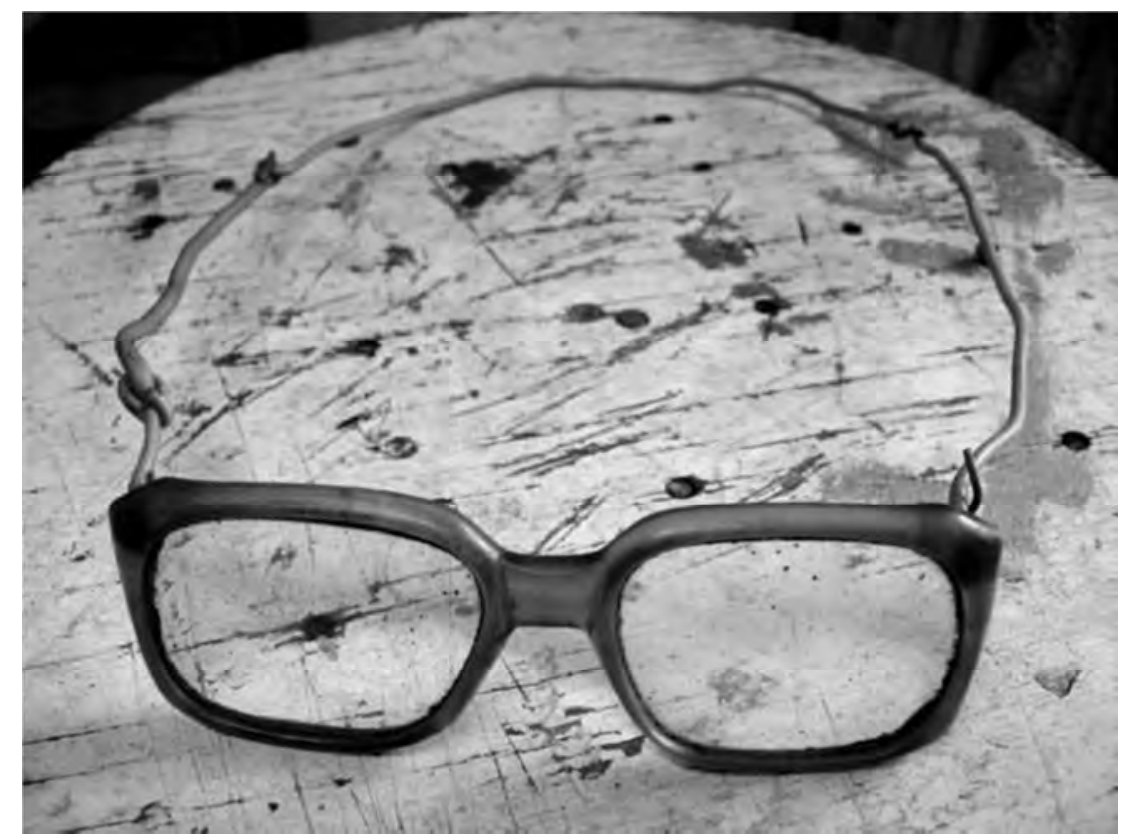

Fonte: Cao Guimarães. 


\section{Figura 5 - A batata-suporte}

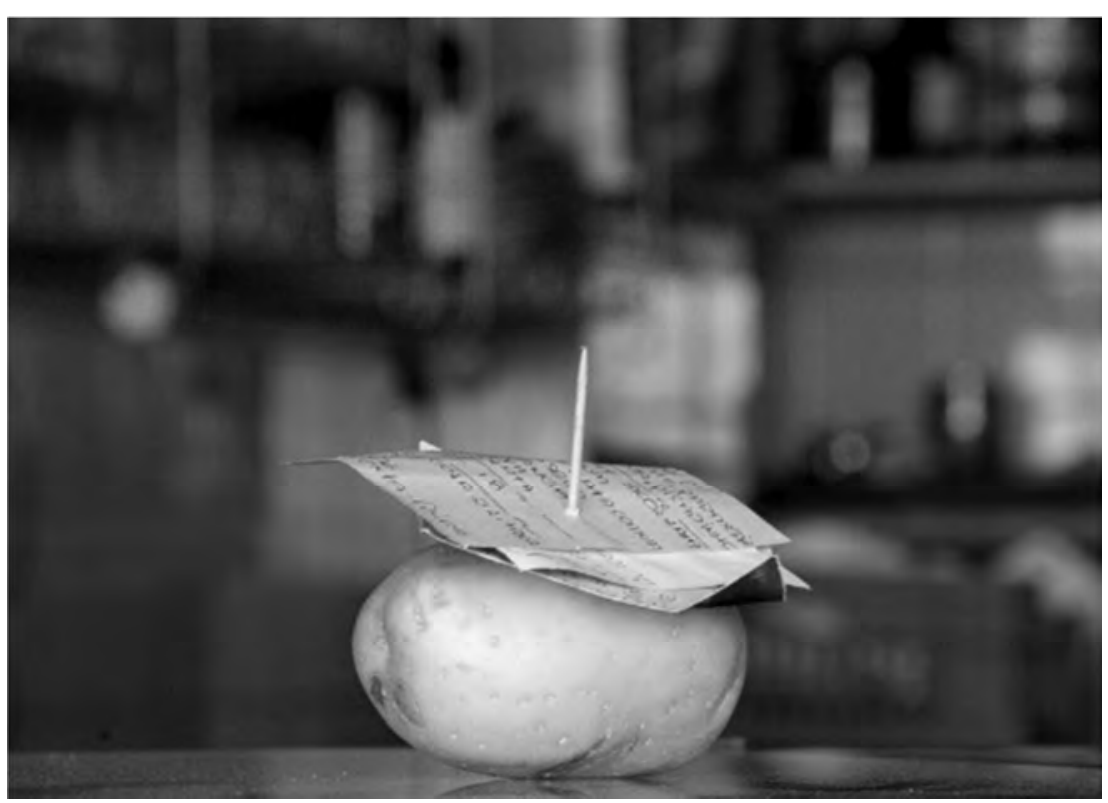

Fonte: Cao Guimarães.

Essas imagens revelam práticas inventivas que permitem a sujeitos lidar com problemas cotidianos, que vão da quebra dos óculos ao desconforto de dormir sem um apoio para a cabeça. As fotos evidenciam a criatividade de sujeitos para lidar, de formas inesperadas, com situações que se lhes apresentam.

O estudo de Rodrigo Boufleur sobre gambiarras ajuda a compreender melhor esse universo de práticas ao propor uma tipologia das diferentes formas de gambiarra. Partindo de uma perspectiva da cultura material e do design de produtos, o autor relaciona os critérios de função e forma para delimitar os diferentes tipos de intervenções, que podem alterar a forma mantendo ou não a mesma função (como os óculos-arame ou o sutiã-clipado), mudar a função sem alteração de forma (como o travesseiro-coco), ou ainda criar um novo artefato reaproveitando outros (como a batata-suporte). Tais categorias nos permitem visualizar o amplo espectro de possibilidades que assume a intervenção humana sobre os objetos.

Diante dessa diversidade de fenômenos, Cao Guimarães propõe pensar as gambiarras para além da dimensão “objeto”, enxergando, sobretudo, a ação prática que as envolve. 
Eu comecei a perceber a possibilidade de categorias de gambiarras, e a ampliação do conceito de gambiarra. Aí a gambiarra deixa de ser só um objeto, ou uma ação pra consertar uma coisa, e torna-se uma atitude, uma forma de vida. Aí você pode ampliar o conceito pra várias esferas. Tipo o cara que deita a cabeça num coco, é um gesto-gambiarra. Não é um objeto-gambiarra. ${ }^{9}$

Ricardo Rosas também lembra a necessidade de pensar a gambiarra de uma forma ampliada. De acordo com ele, a gambiarra

não necessariamente implica um "produto final", pois também é processo, um work in progress. Talvez o processo seja mais importante exatamente porque a gambiarra nunca é final, sempre há algo para acrescenta ou aprimorar. No entanto, há algo mais. [...] a gambiarra também é método. É modo, modus operandi, tática de guerrilha, de ação, de transmissão, de disseminação. ${ }^{10}$

Nesse sentido, é possível pensar as gambiarras sempre como práticas ou gestos. Mesmo quando ela assume a forma visível de um objeto (um óculos, cuja armação foi consertada com um arame, por exemplo) ${ }^{11}$ [imagem 4], ela evidencia uma manifestação material de uma ação que desloca formas de percepção e de relação com o mundo. Justamente por isso, conseguimos pensar em muitas circunstâncias em que a gambiarra não se materializa em objetos, mas reside na própria fugacidade do gesto. Usar um lápis para amarrar o cabelo, colocar um celular dentro de um liquidificador para ampliar o som ao ouvir música entre amigos, os improvisos diários na cozinha quando falta algum utensílio ou ingrediente, são exemplos corriqueiros dos gestos-gambiarra. A gambiarra está na prática, evidenciando a capacidade de pessoas ordinárias de criar, produzir, inventar e resistir às lógicas vigentes (como a do consumo perecível e a do uso padronizado dos objetos).

Entendemos, assim, que tanto os objetos quanto os gestos fazem parte de um "processogambiarra”, que atravessa toda essa prática. Entender a gambiarra como processo significa apreender como o "modo de fazer" implica reapropriação de ideias ou materiais e alguma dose de improviso e criatividade para lidar com as necessidades específicas. Remetendo, por exemplo, ao trabalho de Cao Guimarães, é fácil perceber a forma como o 
processo-gambiarra aparece na própria realização de sua série fotográfica. As fotos foram feitas em diversos países, durante viagens do artista, de forma frequentemente improvisada, como ele mesmo afirma:

eu estava fotografando isso com câmeras horríveis, não tem uma estetização do quadro, da composição, da imagem. É simplesmente uma documentação do objeto (...) É por isso que a força ali está no grupo. Você não fica contemplando uma foto de uma gambiarra (risos), assim, ela é mais legal quando você vê o grupo, e aí você começa a perceber uma forma de olhar o mundo... ${ }^{12}$

Desse modo, o termo "estética da gambiarra" parece conter um duplo sentido: a gambiarra sendo repensada de forma a fazer aflorar um potencial estético a partir da agregação das fotos; e uma estética diferente da que é trabalhada normalmente pelo artista, resultado de um processo-gambiarra, que passa de uma plasticidade pensada de antemão para um trabalho feito com o que se tem à mão. Ao trabalhar assim, o artista opera de forma coerente com gestos que retrata.

Ademais, ao dar visibilidade a essas gambiarras em sua processualidade, artistas como Cao Guimarães ressaltam o gesto estético-político nelas contido. Como bem aponta D'Ambrosio:

\footnotetext{
Dar ao improviso o status de arte denuncia uma forma de ver o dia-a-dia como um potencial universo de transformação da realidade. Nesse aspecto, treinar o olhar para observar essas particularidades torna-se algo importante, pois expressa como a mesmice que ronda boa parte dos trabalhos plásticos pode ser combatida pela habilidade simples - mas fundamental - de saber ver e refletir sobre o mundo circundante. ${ }^{13}$
}

Para discutir a potência política desse processo, faremos dois movimentos no presente artigo. No primeiro deles, reconstruiremos o argumento de Michel de Certeau sobre a inventividade do cotidiano. Na sequência, abordaremos a relação entre estética e política nos trabalhos de Rancière e Dewey (bem como, muito sucintamente, de Arendt), salientando a potência das singularidades na reconstrução do comum. Reiteramos, pois, o 
propósito conceitual do presente ensaio, que não busca realizar um estudo empírico sobre obras, exposições ou práticas cotidianas, mas tomá-las como ponto de partida para reflexão sobre a dimensão política do fenômeno mais amplo chamado gambiarra.

\section{Uma prática da vida cotidiana}

Pensando a gambiarra como uma prática de ressignificação de materiais e sentidos, faz-se interessante, em primeiro lugar, retomar as discussões do pensador francês Michel de Certeau. A Invenção do Cotidiano é resultado de um longo trabalho de pesquisa realizado entre 1974 e 1978, baseado em entrevistas e observações de campo acerca de temas tão diversos, como as maneiras de ler, caminhar, escrever e cozinhar. A obra tenta "dar a palavra" ao "homem comum", como evidencia a dedicatória de seu primeiro tomo: "este ensaio é dedicado ao homem [sic] ordinário. Herói comum. Personagem disseminada. Caminhante inumerável” (CERTEAU, 2000, p.58).

Ao se debruçar sobre as atividades da vida comum, o autor aposta na ideia de que os homens ordinários, essa multidão de indivíduos sem nome, usuários de produtos e receptores de informações, agem sobre as estruturas de poder nas quais estão imersos. As pessoas comuns constroem e reinventam, cotidianamente, o mundo em que vivem. Assim, como apontava Luce Giard no prefácio do livro: "Sempre é bom recordar que não se devem tomar os outros por idiotas" (2000, p.19).

Nesse sentido, Certeau se interroga sobre as operações, fugidias e fundamentais, dos usuários, desejando, com isso, fazer com que as maneiras de fazer deixem de ser "o fundo noturno da atividade social" (CERTEAU, 2000, p.37). É importante ressaltar, no entanto, que o exame das práticas e o foco nos homens comuns não significam um regresso teórico aos indivíduos. Certeau critica o atomismo social. É a relação social que determina os termos deste estudo, e, nesse sentido, cada individualidade é vista, aqui, como o lugar em que se faz presente a "pluralidade incoerente de suas determinações relacionais" (CERTEAU, 2000, p.38). Seu objeto de estudo são os modos de operação e não seus autores. 
Importante frisar, ainda, que essa atenção às práticas cotidianas e à agência criativa da humanidade não implica uma negligência às estruturas sociais e a seu poder. Michel de Certeau dialoga diretamente com Foucault para mostrar que essas estruturas existem, embora o estudo delas não dê conta de explicar a complexidade das práticas humanas. Em Vigiar e punir (1975), Foucault percebe que o poder não deve ser visto como algo concentrado, possuído por um grupo ou indivíduo dominante. O poder é concebido "mais [como] uma rede de relações sempre tensas, sempre em atividade, do que um privilégio que se poderia deter" (FOUCAULT, 1975, p.31). Esse poder fluido, que atravessa e perpassa os indivíduos, manifesta-se também no que o autor chama de "tecnologia política do corpo", que se constitui a partir de certo tipo de saber e de controle do corpo. Segundo Foucault, desde o final do século XVIII, o corpo vem sendo tratado como objeto e alvo de novas técnicas políticas de poder. Nesse contexto, ganham importância as "disciplinas", definidas como "métodos que permitem o controle minucioso das ações do corpo, que asseguram a subjugação constante de suas forças e impõem a eles uma relação de docilidade-utilidade" (FOUCAULT, 1975, p.139). Vemos, então, um poder-saber disciplinar, criando manuais, exercícios, organogramas, maneiras corretas de usar um lápis ou de segurar uma arma.

Michel de Certeau não está interessado em estudar, exatamente, os mecanismos de saberpoder disciplinar que Foucault estudou. Embora os reconheça como existentes, situa-os no campo das estratégias. A estratégia seria uma ação que possui um lugar próprio, em que é organizado e produzido um poder:

\footnotetext{
As estratégias são, portanto, ações que, graças ao postulado de um lugar de poder (a propriedade de um próprio), elaboram lugares teóricos (sistemas e discursos totalizantes), capazes de articular um conjunto de lugares físicos onde as forças se distribuem. (CERTEAU, 2000, p.102)
}

A ação estratégica delimita um objetivo, estabelece regras e modos de procedimento. Ela possui a capacidade de produzir e impor. Uma cidade pode ser criada a partir de ações estratégicas de planejadores urbanos - um lugar de poder (a cidade) onde se elaboram 
lugares teóricos (mapas), capazes de articular lugares físicos (ruas, bairros), em que as forças se distribuem.

No entanto, sabemos que as cidades não funcionam da maneira como foram planejadas ou pensadas a partir de uma maquete. Quando estamos caminhando pelas ruas, não seguimos os caminhos traçados de antemão. É no bojo do processo de apropriação desses espaços, que emergem e se insinuam as táticas, como forma de lugares praticados.

Sem lugar próprio, sem visão globalizante, cega e perspicaz como se fica no corpo a corpo sem distância, comandada pelos acasos do tempo, a tática é determinada pela ausência de poder assim como a estratégia é organizada pelo postulado de um poder (CERTEAU, 2000, p.101).

Certeau está interessado nas táticas. Sem o postulado de um poder próprio, elas não podem ter um projeto global, circunscrever seus objetivos num espaço distinto e visível, produzir um discurso totalizante para basear suas ações. Elas se fazem nas ocasiões, aproveitando o tempo oportuno, já que não possuem um espaço delimitado:

Este não-lugar lhe permite sem dúvida mobilidade, mas numa docilidade aos azares do tempo, para captar no vôo as possibilidades oferecidas por um instante. Tem que utilizar, vigilante, as falhas que as conjunturas particulares vão abrindo na vigilância do poder proprietário. Aí vai caçar. Cria ali surpresas. Consegue estar onde ninguém espera. É astúcia (CERTEAU, 2000, p.100).

Muitas das nossas práticas cotidianas são táticas porque não implicam mera absorção das estruturas de poder existentes: elas reinventam tais estruturas, na medida em que se apropriam delas. Michel de Certeau atenta para a existência de uma produção também no momento do consumo/apropriação. Essa produção apropriativa não apresenta um lugar preciso, em que isso seja facilmente visto; ela é dispersa, quase invisível, e gera modos de usar a ordem dominante. Certeau aposta no potencial de resistência desses procedimentos populares "minúsculos e cotidianos", que jogam com os mecanismos da disciplina. 
É no contexto das táticas que se inserem as gambiarras. Como práticas de ressignificação e reapropriação, elas podem tanto dar lugar a novos objetos, como podem atribuir funções diferentes aos objetos à nossa disposição. Recorrendo, novamente, a um exemplo do ensaio de Cao Guimarães, tem-se uma batata agregada a um palito para armazenar os pedidos dos clientes na mesa de um bar [imagem 5]. Ressignificados, ambos os objetos adquirem nova função, por um gesto inventivo. Era justamente o que Certeau via na base das táticas: essa capacidade criativa de reinventar um mundo supostamente estabelecido, deixando marcas singulares na construção coletiva em que estamos imersos.

Táticas essas que surgem da ocasião, aproveitando o tempo oportuno. Nas palavras de Cao Guimarães, a composição do ensaio fotográfico foi um "trabalho muito de captura de imagens, que eu não sei quando que eu vou encontrar". Ou seja, o próprio registro das gambiarras se assemelha a uma tática, no que tange esse caráter de oportunidade, ocasião.

Tendo em vista essa dimensão tática das gambiarras, compreendemos que ela apresenta uma dimensão política anti-disciplinar. Ela revela a capacidade de agência dos indivíduos, fazendo um contraponto à ideia foucaultiana dos corpos dóceis, passivos e adestrados pela disciplina. Não se trata de uma manifestação ou reivindicação discursiva contra as regras de um sistema político-econômico-social, ou de um discurso que propõe mudanças no plano simbólico. As práticas são concretas: ao experienciar/realizar uma gambiarra, ressignificamos "modos de usar"14 (e, com eles, valores e normas) com os quais estamos habituados. Justamente por isso, faz-se necessário entender a dimensão política dessa arte do fazer, a qual se liga fundamentalmente à sua dimensão estética.

\section{Dimensão estética e política da experiência cotidiana}

Para tratar dos aspectos estéticos e políticos da gambiarra, vamos utilizar o pensamento de Jacques Rancière acerca da "partilha do sensível". Também retomaremos as teorias de John Dewey em A arte como experiência, para vincular a experiência estética às práticas da vida cotidiana, dentro das quais está inserida a gambiarra. Por fim, buscaremos mostrar, brevemente, como algumas ideias trabalhadas por Hannah Arendt podem 
oferecer uma interessante articulação entre pontos trabalhados pelos supramencionados autores.

Rancière trabalha, ao longo de diversas obras ${ }^{15}$, o conceito de "partilha do sensível", noção fundamental que permite pensar a estética como base da política. Em Políticas da escrita, conjunto de ensaios publicado em 1995, ele apresenta uma definição do conceito:

\begin{abstract}
Partilha significa duas coisas: a participação em um conjunto comum e, inversamente, a separação, a distribuição dos quinhões. Uma partilha do sensível é, portanto, o modo como se determina no sensível a relação entre um conjunto comum partilhado e a divisão de partes exclusivas. Antes de ser um sistema de formas constitucionais ou de relações de poder, uma ordem política é uma certa divisão das ocupações, a qual se inscreve, por sua vez, em uma configuração do sensível: em uma relação entre os modos do fazer, os modos do ser e os do dizer; entre a distribuição dos corpos de acordo com suas atribuições e finalidades e a circulação do sentido; entre a ordem do visível e a do dizível (RANCIÈRE, 1995, p.7-8 apud GUIMARÃES, 2013, p.61).
\end{abstract}

A partilha do sensível tem um duplo sentido, tanto de um mundo sensível compartilhado, quanto de uma distribuição das ocupações e capacidades desse mundo sensível comum o que se pode ver, dizer ou fazer está (desigualmente) distribuído entre aqueles que o compartilham. Rancière (2012, p. 17) pontua que tal partilha é uma "distribuição apriorística das posições e das capacidades e incapacidades vinculadas a essas posições", o que permite a alguns fazer coisas que outros não podem fazer. Ou seja, ao dividir, distribuir o mundo sensível que é partilhado, configura-se uma certa cartografia estética, em que uns têm acesso a certos modos de fazer, dizer ou ser, em determinados espaços, enquanto outros não têm.

Para Rancière (2014, p.147), a política é fundamentalmente "uma intervenção sobre o visível e o enunciável". Ela não é o conjunto de processos e instituições que ordenam a coletividade e distribuem lugares e funções. A isso, Rancière dá o nome de polícia. A política, por sua vez, emerge da ruptura com as configurações existentes, evidenciando a conta sempre malfeita na partilha do sensível, por meio da reivindicação da parte dos sem parte. É justamente por isso que, para ele, a "política não é feita de relações de poder, é feita de relações de mundos" (1996, p. 53). Como apontam Lelo e Marques (2014, p. 
371), "a partilha do sensível promovida pela política visa retirar os corpos de seus lugares assinalados, configurando uma comunidade de partilha e libertando-os de qualquer redução à sua funcionalidade".

Nessa perspectiva, estética e política são indissociáveis. Em uma entrevista concedida em 2009, Rancière aponta que a "estética e a política são maneiras de organizar o sensível: de dar a entender, de dar a ver, de construir a visibilidade e a inteligibilidade dos acontecimentos". ${ }^{16} \mathrm{O}$ mundo sensível é percebido e experienciado de formas distintas de acordo com a "distribuição social": a configuração do sensível define uma forma, uma estética para o mundo político. ${ }^{17}$ Os modos de percepção e sensibilidade, a maneira pela qual os indivíduos e grupos constroem um mundo social intersubjetivo, conferem dimensão estética ao mundo partilhado.

A política, assim como a arte, pode reconfigurar a partilha do sensível e redefinir essa estética. A arte e a política se fundam sobre a produção e sobre os "rearranjos materiais dos signos e das imagens, das relações entre o que se vê e o que se diz, entre o que se faz e o que se pode fazer" (RANCIÈRE, 2005, p.59). Elas têm o potencial de deslocar os lugares já estabelecidos na partilha do sensível, fazer ver o que não era visto, suspender as formas ordinárias da experiência sensível, possibilitar novas experiências e propor novos arranjos na distribuição política-estética do mundo sensível.

Essa conexão constitutiva entre política e estética também fora amplamente explorada no pensamento de John Dewey, ainda que por caminhos baseados em uma matriz filosófica bastante distinta. O pragmatista norte-americano elaborou um complexo sistema filosófico em que tenta articular uma crítica à metafísica clássica, uma epistemologia, uma teoria moral, uma teoria política e uma teoria estética. $\mathrm{Na}$ base desse sistema filosófico, está o reconhecimento da experiência como forma de constituição recíproca de seres humanos e do ambiente em que se inserem. É no engajamento do sujeito com o mundo que ambos se constituem.

Dentro desse sistema filosófico, John Dewey faz profunda discussão sobre estética em seu clássico Arte como experiência, que agrega uma série de aulas proferidas na Universidade de Harvard em 1931. Dewey argumenta que a experiência estética deve ser 
entendida como uma continuidade da experiência cotidiana. Para ele, a arte, como um processo, não se resume à sua concretização em um "objeto expressivo" (à obra de arte). Por isso, ele critica a concepção compartimentalizada da arte, isolada em museus e galerias, recolhidas e armazenadas pelo "colecionador típico" e produzida pela figura do "artista excêntrico" que exagera sua separação em relação ao mundo. Dewey aponta para "um abismo entre a experiência comum e a experiência estética" (DEWEY, 2010, p.69) na sociedade moderna e pretende "recuperar a continuidade da experiência estética com os processos normais do viver" (DEWEY, 2010, p. 70).

Segundo o autor, a obra de arte não seria algo separado na vida cotidiana, mas simplesmente algo que desenvolve e acentua as coisas que dão prazer no dia-a-dia:

\footnotetext{
Para compreender o estético em suas formas supremas e aprovadas, é preciso começar por ele em sua forma bruta; nos acontecimentos e cenas que prendem o olhar e o ouvido atentos do homem, despertando seu interesse e lhe proporcionando prazer ao olhar e ouvir (DEWEY, 2010, p.62).
}

Resta a questão do que seria essa experiência comum, e por que a experiência estética poderia emergir dela. Dewey nos lembra que qualquer experiência está relacionada a um meio, não apenas por se inserir nele, mas por estar em interação com ele. Assim "a criatura viva" está sempre exposta aos perigos do meio e deve utilizar-se dele para satisfazer suas necessidades. Quando o ser vivo supera as tensões e conflitos, as rupturas e reencontros dos quais é feito o mundo real, sua experiência se torna passível de qualidade estética.

A experiência é um processo contínuo, que faz parte do viver e estar no mundo da "criatura viva". Entretanto, o autor aponta que viver experiências é diferente de ter uma experiência. Essa diferença estaria marcada, justamente, pela singularidade. Uma experiência singular ocorre "quando o material vivenciado faz o percurso até a sua consecução" (DEWEY, 2010, p.109), quando não há interrupção, distração ou dispersão. "Então, e só então, ela é integrada e demarcada no fluxo geral da experiência proveniente de outras experiências" (DEWEY, 2010, p.109-110). Essa experiência “demarcada é um todo e carrega em si seu caráter individualizador e sua autossuficiência" (DEWEY, 2010, 
p.110). Mas essa autossuficiência característica da experiência singular não significa um isolamento; pelo contrário, ela implica uma acentuação da vitalidade:

em vez de significar um encerrar-se em sentimentos e sensações privados, significa uma troca ativa e atenta com o mundo; em seu auge, significa uma interpenetração completa entre o eu e o mundo dos objetos e acontecimentos (DEWEY, 2010, p.83).

Assim, a experiência estética está relacionada ao presente e à presença: na arte, o passado reforça o presente, e o futuro intensifica o que existe agora; e a fonte dessa experiência está ligada a um estado de atenção e de presença com nós mesmos e o que está à nossa volta. A experiência comum e a estética são, portanto, indissociáveis: a experiência de estar no mundo seria como a arte em seu estado germinal, e cada experiência poderia conter a promessa da percepção prazerosa de uma experiência estética. $\mathrm{O}$ estético não é o que está isolado para contemplação, mas o que nos envolve no mundo. Mais uma vez, a estética e a política se interpenetram: a relação de presença e envolvimento nesse mundo social partilhado, bem como a possibilidade de agir sobre ele, configura uma experiência política. A experiência estética é, portanto, também política.

$\mathrm{Na}$ arquitetura conceitual formulada por John Dewey, a experiência estética tem o potencial de romper formas usuais e automatizadas de percepção da realidade, descortinando novos mundos possíveis. A experiência estética é desestabilizante e, por isso, indutora de reflexividade. Isso não significa que Dewey busque restringir o potencial político da estética à sua dimensão cognitiva. Ao contrário, ele expande os quadros da reflexividade humana, atentando para o modo como o refazer de nossas práticas envolve um contínuo teste de hipóteses sobre a natureza do mundo e seus padrões de funcionamento. Ao nos reconectar com dimensões negligenciadas do mundo, o estético nos aponta novas hipóteses, capazes de reconfigurar nossas interações com a concretude do mundo de um modo geral e com os outros de modo mais específico. Não há dúvidas de que tal processo tem profundas implicações políticas, sobretudo se se define política em uma visada ampla como aquilo que diz respeito à existência comunal. 
Nesse sentido, tanto Dewey como Rancière, por vias e bases filosóficas distintas, apontam para o potencial expressivo da experiência comum e sugerem que a arte e a política podem se valer disso para ressignificar e rearranjar o próprio mundo sensível. Dewey assinala que "a luta constante da arte, portanto, é converter materiais que gaguejem ou emudeçam na experiência comum em veículos eloquentes” (Idem, p.403). E Rancière, de forma semelhante, fala que a atividade artística, assim como a política, "faz ver o que não cabia ser visto, [...] faz ouvir como discurso o que só era ouvido como barulho" (RANCIÈRE, 1996, p.42).

Para deixar ainda mais clara essa conexão entre estética e política, convém recorrer, por fim, e muito brevemente, a algumas ideias exploradas por Hannah Arendt (2005). A autora afirma que a política se faz na capacidade humana de produção do novo ao longo da permanente tessitura de um mundo comum. O princípio da natalidade diz respeito a essa potência humana de inovar e de buscar a expressão da singularidade nos quadros de uma rede simbólica partilhada que precede aos sujeitos e os constitui.

Para explorar tais ideias, Arendt trabalha com o conceito de espaço público, argumentando que a existência do mundo partilhado depende de sua visibilidade. Em Arendt, a aparência é, pois, constitutiva do ser, e a concretude do mundo depende de sua capacidade de sobrevivência a uma pluralidade de olhares. A pluralidade, como base da condição humana, permite que os indivíduos, embora construídos socialmente, afetem as estruturas da sociedade e busquem deslocá-las. Deslocamento esse que passa pela mudança na forma como as coisas se manifestam. Mudanças na aparência não são superficiais, mas podem alterar os próprios alicerces ontológicos do mundo partilhado.

\section{Política e estética da gambiarra}

Expostas as ideias de Rancière, Dewey e Arendt, cabe-nos agora, retornar às gambiarras. A gambiarra é uma prática cotidiana que dialoga amplamente com as noções aqui discutidas. Em nossa partilha do sensível, na qual se distribuem lugares e capacidades como as do produtor (ativo) ou do consumidor (passivo), a gambiarra aparece como uma 
suspensão nessa oposição e como um deslocamento da experiência corriqueira. $O$ consumidor, aqui, toma posição de agente ativo, cria novas formas de uso, ressignifica produtos e rearranja materiais distintos. Dessa forma, ele expressa uma experiência singular. A prática da gambiarra rearranja não apenas materiais da vida cotidiana, mas também a própria partilha do sensível, os lugares fixados para cada corpo, os usos destinados para cada produto, os modos de operar já codificados. Trata-se de um rearranjo da matéria que ressignifica simbolicamente a realidade, alterando fragmentos do mundo comum.

Rancière afirma que "os processos de emancipação que funcionam são aqueles que tornam as pessoas capazes de inventar práticas que não existiam ainda" (RANCIÈRE, 2010$, s/p. $)^{18}$. Em sua visão, as rupturas que promovem deslocamentos efetivos são aquelas que permitem ver o que não era visto e transformam em discurso o que era tido como ruído. Isso faz pensar nas táticas de Michel de Certeau, nos procedimentos populares minúsculos e cotidianos que jogam com os mecanismos da disciplina, propondo novos modos de fazer, reiventando o presente e o cotidiano. A gambiarra parece apontar para uma tática de resistência e um processo de emancipação no sentido de deslocar o lugar de consumidor passivo e ser capaz de inventar novas práticas e novas "artes do fazer".

Os objetos e práticas recriados nos processos-gambiarra mostram a capacidade humana de intervir criativamente no mundo, reconstruindo horizontes de possíveis. É comum que nos peguemos sorrindo diante de uma gambiarra, como que encantados com a simplicidade da astúcia de alguém que ousou reinventar o cotidiano. Essa astúcia parece mostrar não apenas que outro mundo é possível, mas também que nós somos capazes de produzir esses outros mundos. O objeto, curiosamente, tem o potencial de devolver-nos a percepção de nossa agência humana.

Essa capacidade de agência humana, tão cara a Dewey e a Arendt, revela-se na reinvenção do cotidiano, que decorre de nossa capacidade de, ao mesmo tempo, sofrer e agir sobre o mundo. Os problemas que o mundo oferece, as contingências - como coloca Dewey - são um convite à reflexão e à busca, através da "prática de testes", de novas soluções, que podem surgir de forma improvisada. Assim, estamos constantemente 
testando e reinventando. Ao fazê-lo, podemos redimensionar, estética e politicamente, esse mundo partilhado e intersubjetivo. Os óculos-arame, o travesseiro-coco e a batatasuporte são todos exemplos da ação humana a recriar o mundo. A gambiarra, enquanto objeto, gesto ou processo, é evidência, indício e concretização dessa capacidade humana, lembrando-nos não apenas da contingência do mundo, mas da possibilidade de intervir sobre ele.

O mundo, como percebe Dewey, é construído pelos seres humanos - pela prática -, mas oferece resistências. Tais resistências emergem da concretude do mundo, que impõe certos limites à nossa agência. Para Dewey, um mundo sem resistência, "ininterruptamente favorável à realização imediata de nossas impulsões poria fim ao crescimento, tão certo quanto um meio sempre hostil seria irritante e destrutivo" (DEWEY, 2010, p.145). É a resistência - o problema colocado pela concretude do mundo - que nos faz buscar soluções. É isso que fornece o material e o contexto para vivenciarmos experiências singulares, e possivelmente estéticas. O problema surge como essa ruptura na continuidade da experiência que possibilita reinventar o cotidiano, organizando novas e originais formas de fazer e sentir o mundo.

A gambiarra se oferece, simultaneamente, como elemento desestabilizador e como solução para certos problemas. É justamente por isso que podemos pensá-la como prática que desloca nossas formas de percepção e altera os regimes de partilha do sensível. A gambiarra concretiza (em objetos e gestos) uma alteração na forma como lugares e capacidades são distribuídos, tornando visível a arte do fraco, suas táticas e astúcias. Mais do que uma solução paliativa para um problema pontual, a gambiarra emerge como manifestação visível de outros modos de fazer (de dizer ou de ser), remapeando nosso mundo comum. Os processos-gambiarra, em suma, criam as condições para a percepção (estética e política) de que outro mundo é possível.

É preciso lembrar, aqui, que a fonte da experiência estética, como aponta Dewey (2010), está ligada a um estado de atenção ao entorno e de presença efetiva no mundo. As gambiarras não são realizadas necessariamente com um objetivo propriamente estético. Nesse sentido, o olhar de artistas, como Cao Guimarães, busca transformar essas práticas 
que gaguejam em veículos eloquentes (DEWEY, 2010, p.403) que nos convocam a perceber esses deslocamentos construídos cotidianamente.

\begin{abstract}
Ninguém assina a gambiarra, é um recorte que eu fiz. A obra não é a gambiarra, a obra é a foto que eu fiz da gambiarra. A gambiarra... o cara fez lá pra arrumar a casa dele, estava vazando água e ele arrumou o cano daquele jeito né; mas a questão não é o espelhinho que ele botou no banheiro dele, ele acha aquilo normal. O pulo do gato está em você olhar praquilo e dizer: "não, isso aqui eu vou tirar daqui e fazer uma foto disso e vou botar pras pessoas verem". 19
\end{abstract}

Obviamente, contudo, não é apenas o artista, enquanto profissional, que tem a capacidade de olhar para o mundo de forma a transformá-lo em uma experiência estética. O estado de presença e atenção é, potencialmente, acessível a todos, e pode transformar o modo como experienciamos o mundo. As gambiarras existem justamente porque as pessoas se fazem presentes no mundo, apropriando-se dos materiais que estão à sua volta e criando a partir deles. Assim, as pessoas expressam suas singularidades e reinventam, criativamente, o contexto em que se inserem. E o fazem coletivamente, por meio dessa criatividade partilhada anonimamente.

Em termos arendtianos, pode-se perceber a gambiarra, portanto, como forma de ação, que atualiza o princípio da natalidade ao recriar fragmentos de um mundo comum que nos precede e nos sucede (ARENDT, 2005). O processo-gambiarra permite aos sujeitos intervir no mundo regulado e estruturado em que se inserem, atuando efetivamente como sujeitos.

Se essa expressão do singular é política, cabe frisar que a percepção dessa expressão também é de extrema relevância política. Como forma simbólica fruída e experienciada pelos demais atores sociais, a gambiarra permite que os sujeitos se deem conta dessa capacidade de agência. Dessa forma, ela pode deslocar a naturalidade do mundo, expondo sua natureza contingente, transformável e imprevisível. Ao devolver a incerteza ao mundo, a gambiarra possibilita indicar que outros mundos são possíveis. $O$ questionamento da naturalidade revitaliza a potência de produzir algo novo. 
Assim, sem deixar de reconhecer o aspecto funcional da gambiarra, tentamos pensar essa prática da vida cotidiana em esferas que extrapolam a necessidade ou a precariedade econômica. Através dessa criatividade prática, a gambiarra vocaliza um potencial de transformação da realidade. Transformação essa que nasce da expressão da singularidade humana, em sua capacidade de gerar o novo.

\section{Considerações finais}

Este texto buscou discutir a dimensão política das gambiarras. Ele partiu da constatação de um crescente interesse pela prática, para abordá-la conceitualmente. Nesse percurso, definiu-se a gambiarra como um processo, fundado em uma prática de apropriação inventiva do mundo.

Para compreender esse processo, recorremos à discussão de tática em Michel de Certeau, à teorização sobre política e partilha do sensível em Rancière, ao tratamento dado por Dewey aos conceitos de experiência e estética, e às noções de ação, mundo comum e natalidade em Hannah Arendt. Partindo de diferentes lugares de fala filosóficos, todos esses autores salientam a centralidade da singularidade humana na recriação do mundo comum, operando com uma concepção ampla de política.

Nesse sentido, buscamos argumentar que as gambiarras são táticas, na medida em que oferecem novas possibilidades e novos modos de fazer, revelando as potências da "criatura viva", para usar um termo Deweyano. Daí o interesse artístico nessas formas, e a possibilidade dessas práticas de rearranjar nossa partilha do sensível. A gambiarra concretiza uma rearticulação em uma ordem já estabelecida do que se dá a ver e a ouvir no nosso mundo e, assim, implica um primeiro passo de estranhamento, de suspensão nessa ordem, para que os lugares fixos sejam deslocados e experienciados de uma nova forma. Como forma de expressão humana, a gambiarra permite a manifestação da singularidade individual (e da pluralidade humana) em um mundo partilhado. 
Do ponto de vista da comunicação e política, o argumento aqui apresentado permite pensar essa interface de forma ampliada, ultrapassando objetos de estudo convencionais e enfoques mais tradicionais. Refletir, simultaneamente, sobre a dimensão estética da política e sobre a dimensão política da estética implica compreender os modos como práticas as mais diversas se configuram como processos comunicacionais potencialmente capazes de promover alterações na tessitura coletiva do mundo comum. A gambiarra ajuda-nos a entender o modo como sujeitos continuam a agir, criativamente, na reinvenção política do mundo que partilham.

\footnotetext{
Notas

${ }^{1}$ Ver HOUAISS, Antônio. Dicionário da Língua Portuguesa. São Paulo: Objetiva, 1999.

${ }^{2}$ Apresentada no Centro Cultural Banco do Brasil RJ em 2003 e no Instituto Tomie Othake SP em 2004.

3 Integrantes da exposição: Jarbas Lopes, Efrain Almeida, Marepe, Ducha e Capacete Entretenimentos.

${ }^{4}$ Alguns dos trabalhos mencionados: a Bicicleta Maracatu, de Paulo Neflidio, o Projeto Spio, de Lucas Bambozzi, e os ateliês de EtienneDelacroix, na Universidad de la República, em Montevidéu. Texto disponível em:

<http://www2.sescsp.org.br/sesc/videobrasil/up/arquivos/200611/20061117_160212_CadernoVB 02_p.36-53_P.pdf>. Acesso em: 19/04/2013.

${ }^{5} \mathrm{O}$ coletivo é formado por Lucas Mafra, Fred Paulino e Paulo Henrique Ganso Pessoa.

${ }_{7}^{6}$ Disponível em: <http://www.gambiologia.net/blog/about/>. Acesso em: 19/04/2013.

7 Esta série foi um dos pontos de partida que motivaram as reflexões desenvolvidas neste ensaio. É preciso esclarecer, contudo, que este texto não se propõe a analisar a referida obra.

${ }^{8}$ As imagens referidas foram publicadas no livro artístico Gambiarra. Trata-se de uma publicação de 600 exemplares que integra uma série de livros de artista editados para a $2^{\underline{a}}$ Trienal Poli/Gráfica de San Juan: América Latina e Caribe, em 2009, organizada pelo Instituto de Cultura Puertorriqueña. Editor/curador: Adriano Pedrosa.

${ }^{9}$ Entrevista concedida a um dos autores em 26 de novembro de 2012.

${ }^{10}$ ROSAS, Ricardo, "Gambiarra: alguns pontos para se pensar uma tecnologia recombinante", p.6, Disponível em:

<http://www2.sescsp.org.br/sesc/videobrasil/up/arquivos/200611/20061117_160212_CadernoVB 02_p.36-53_P.pdf>, acesso em: 19/04/2013.

${ }_{11}^{1}$ Imagem publicada no livro artístico Gambiarra, de Cao Guimarães.

${ }^{12}$ Entrevista concedida a um dos autores em 26 de novembro de 2012.

${ }^{13}$ D'AMBROSIO, Oscar, "Gambiarras poéticas", disponível em:

$<$ http://www.caoguimaraes.com/page2/principal_new.php>. Acesso em: 19/04/2013.

${ }^{14} \mathrm{Em}$ francês, a expressão "mode d'emploi" (modo de usar) refere-se aos manuais de instrução de produtos em geral.

${ }^{15}$ O conceito aparece em Políticas da escrita (1995), O desentendimento: política e filosofia (1996), Le destindesimages (2003), Malaisedansl'esthétique (2004), Auborddu politique (2004) e A partilha do sensível (2005).

${ }^{16}$ Disponível em:
}

http://revistacult.uol.com.br/home/2010/03/entrevista-jacques-ranciere/, consultado em: 19/04/2013. 
${ }^{17}$ Sobre as relações entre estética e política na obra de Rancière, ver dissertação de Victor Guimarães, intitulada "A intermitência política do documentário: figurações do hip hop no cinema brasileiro contemporâneo" (2013), p. 57 a 67.

${ }^{18}$ Disponível em:

<http://revistacult.uol.com.br/home/2010/03/entrevista-jacques-ranciere>. Acesso em:

19/04/2013.

${ }^{19}$ Entrevista concedida a um dos autores em 26 de novembro de 2012.

\section{Referências}

ARENDT, Hannah. A condição humana. 10ª ed. Rio de Janeiro: Forense, 2005.

BOUFLEUR, Rodrigo. A Questão da Gambiarra: Formas Alternativas de Produzir Artefatos e suas Relações com o Design de Produtos. 2006. 153p. Dissertação (Mestrado em Urbanismo). Faculdade de Arquitetura e Urbanismo da Universidade de São Paulo, 2006.

CERTEAU, Michel de. A Invenção do Cotidiano: artes do fazer, Petrópolis: Editora Vozes, 2000.

D’AMBROSIO, Oscar. A Poesia da Gambiarra. Disponível em: <http://www.caoguimaraes.com/page2/principal_new.php>. Acesso em: 19 abril 2013.

DEWEY, John. A arte como experiência. São Paulo: Editora Martins Fontes, 2010.

FOUCAULT, Michel. Surveiller et Punir. Paris, Gallimard, 1975.

GUIMARÃES, Victor. A intermitência política do documentário: figurações do hip hop no cinema brasileiro contemporâneo. 2013. Dissertação (Mestrado em Comunicação Social), Faculdade de Filosofia e Ciências Humanas da Universidade Federal de Minas Gerais, 2013.

LELO, T. V. ; MARQUES, A. C. S. Democracia e pós-democracia no pensamento político de Jacques Rancière a partir das noções de igualdade, ética e dissenso. Revista Brasileira de Ciência Política, n. 15, p. 349-374, 2014.

RANCIÈRE, Jacques.Políticas da escrita. Rio de Janeiro: Ed.34, 1995.

. O desentendimento: política e filosofia. São Paulo: Ed.34, 1996.

. A partilha do sensível: estética e política. São Paulo: Ed. 34, 2005.

. O espectador emancipado. São Paulo: Ed. Martins Fontes, 2012.

. Nas margens do político. Lisboa: KKYM, 2014

ROSAS, Ricardo. Gambiarra: alguns pontos para se pensar uma tecnologia recombinante. Disponível em:

<http://www2.sescsp.org.br/sesc/videobrasil/up/arquivos/200611/20061117_160212_CadernoV B02_p.36-53_P.pdf>. Acesso em: 19 abril 2013.

\section{Os autores}

Helena Santos Assunção é mestranda em Antropologia pelo Museu Nacional (UFRJ) e graduada em Ciências Sociais pela UFMG. helena.s.assuncao@gmail.com

Ricardo Fabrino Mendonça é professor do Departamento de Ciência Política da UFMG e doutor em Comunicação (UFMG). ricardofabrino@hotmail.com 